\title{
A river ran through it
}

Ankle-deep streams once burbled across the gently sloping floor of a martian crater, according to the first paper to be published from data gathered by the Curiosity rover at its landing site on Mars (Science 340, 1068-1072; 2013). A Mars with rivers almost certainly supported a complete water cycle: temporary or permanent lakes, whose water evaporated into a thicker atmosphere, and later fell back to ground as rain or snow.

The tell-tale signs of an ancient Mars river were locked in several outcrops of pebbly rock, one of which was spotted by Curiosity the very day it landed in the Gale crater: the pebbles, some of them as large as golf balls, were rounded. Round rocks suggest that flowing fluids have tumbled and abraded larger, angular rocks to smooth their edges, as previously observed only on Earth and on Saturn's moon Titan. That's almost certainly the way Mars made them, too.

The size, roundness and composition of pebbles provide hints of what the Gale crater's streams were like. The streams must have been 3 to 90 centimetres deep

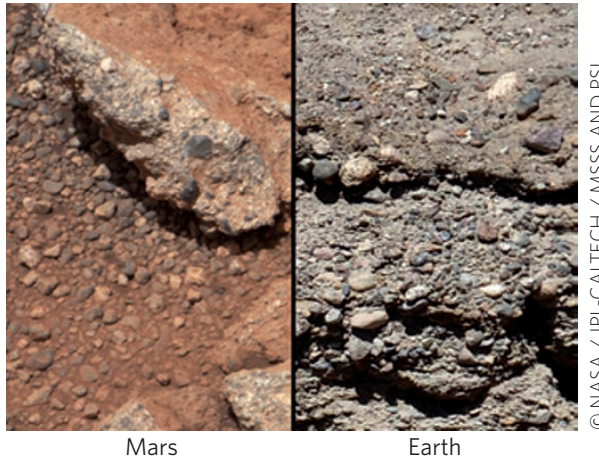

to transport pebbles of that size, and must have flowed for several kilometres to round the grains so. They must have flowed more heavily at some times than others to produce the alternately coarser- and finergrained sediments that make up the layered rock. But they can't have been too wet for too long, because their mineral make-up suggests only weak chemical alteration.

The rough-and-tumble stream environment recorded in Gale's conglomerates is not one that is particularly hospitable to life. But water that flows downhill must eventually pool somewhere, and indeed Curiosity has already found other sedimentary rocks that formed in a quieter environment that - given a supply of carbon-rich chemicals - could have supported life.

One important question remains unanswered: when in Mars's history did these streams tumble their rocks and supply potentially habitable pools? The conglomerates could have been deposited at almost any time after the Gale crater formed 3.5 to 3.8 billion years ago and before Mars arrived at its present geologically quiescent state.

Gale's basin collected a mountain's worth of sediment that has since been deeply incised by wind and water erosion; there may even have been multiple episodes of erosion and infilling. But just how the conglomerates relate to the mountain remains unclear. Fortunately, Curiosity's geological fieldwork continues.

\section{Emily Lakdawalla is based in Pasadena, California, USA, and is Senior Editor for The Planetary Society.}

\section{The journalist's take}

How many times has water been discovered on Mars? Science journalists are increasingly jaded about each breathless announcement trumpeting new evidence for slightly more water, and the public is simply confused. Very few media outlets covered this paper's publication. But that lack of attention is not because of boredom about water on Mars.

In fact, the story had already received wide coverage eight months before publication. In September 2012, fewer than two months after Curiosity's landing, NASA issued a press release and conducted a televised briefing headlined "NASA rover finds old streambed on Martian surface." The images released to the media were from the same data used to create the Science paper figures, and the press panel included four of the paper's authors.

The editorial policy of Science - like that of Nature Publishing Group explicitly enjoins scientists from seeking media attention before publication. Yet the Curiosity mission had little choice but to discuss the conglomerate rocks.
Curiosity is one of three current NASA planetary missions that post all image data returned from the spacecraft on a public website within hours of their receipt on Earth. Anyone with Internet access can follow the ongoing adventures of Curiosity, the Mars Exploration Rover Opportunity, and Cassini (currently in orbit around Saturn), and experience the same breathtaking views of Mars and Saturn that the privileged members of science and operations teams do. To disqualify scientific papers based on prior publication of those images would imply that no Curiosity, Opportunity or Cassini science results based on images could ever be published in Science or Nature.

The missions post data online with compromised quality. 'Raw' images are at full resolution but uncalibrated. Optimizing them for Web distribution wipes out some detail. This reduces the possibility that outside scientists can scoop mission science teams with publications on raw image data. However, some discoveries cannot be obscured by data degradation. The significance of round rocks is obvious to anyone with minimal understanding of geology. Vigilant Internet communities that regularly inspect NASA's latest images were discussing the rocks and their implications within minutes of their release. The news was already out; the Curiosity mission's press briefing established context, explained what the rocks did - and didn't - mean for Mars's potential habitability, and whether such rocks had ever been seen before on Mars (which they hadn't).

The press briefing gave the mission team an early opportunity to show the rest of a sometimes sceptical scientific community, and the public, that the US $\$ 2.5$ billion investment in Curiosity was paying off. Almost all of the scientific results from the Curiosity mission will take years to develop - and it will take painstaking Earth-based empirical work to back up equivocal readings from Curiosity's analytical laboratory instruments. A press release announcing "water on Mars" demonstrated to NASA's critics that Curiosity had been sent to the right place. 